\title{
Volumetric 3-D Vector Flow Measurements using a 62+62 Row-Column Addressed Array
}

Holbek, Simon; Stuart, Matthias Bo; Jensen, Jørgen Arendt

Published in:

Proceedings of 2017 IEEE International Ultrasonics Symposium

Link to article, DOI:

10.1109/ULTSYM.2017.8092004

Publication date:

2017

Document Version

Peer reviewed version

Link back to DTU Orbit

Citation (APA):

Holbek, S., Stuart, M. B., \& Jensen, J. A. (2017). Volumetric 3-D Vector Flow Measurements using a 62+62 Row-Column Addressed Array. In Proceedings of 2017 IEEE International Ultrasonics Symposium IEEE. https://doi.org/10.1109/ULTSYM.2017.8092004

\section{General rights}

Copyright and moral rights for the publications made accessible in the public portal are retained by the authors and/or other copyright owners and it is a condition of accessing publications that users recognise and abide by the legal requirements associated with these rights.

- Users may download and print one copy of any publication from the public portal for the purpose of private study or research.

- You may not further distribute the material or use it for any profit-making activity or commercial gain

- You may freely distribute the URL identifying the publication in the public portal 


\title{
Volumetric 3-D Vector Flow Measurements using a 62+62 Row-Column Addressed Array
}

\author{
Simon Holbek ${ }^{1,2}$, Matthias Bo Stuart ${ }^{1}$, and Jørgen Arendt Jensen ${ }^{1}$ \\ ${ }^{1}$ Center for Fast Ultrasound Imaging, Dept. of Elec. Eng., Bldg. 349, Technical University of Denmark, \\ 2800 Kgs. Lyngby, Denmark \\ ${ }^{2}$ BK Ultrasound, Mileparken 34, 2730 Herlev, Denmark
}

\begin{abstract}
Experimental results from volumetric 3-D vector flow measurements using a 62+62 row-column addressed (RCA) array are presented. A plane-by-plane steered transmit sequence and its post processing steps are described for obtaining 3-D vector flow in a volume. A modified version of the transverse oscillation (TO) velocity estimator is used, which exploits the focal lines generated with the tall elements of a RCA array. Validation of the method is made in a flow-rig system where circulating blood mimicking fluid produced a steady parabolic flow profile with a flow rate of $13.7 \mathrm{~mL} / \mathrm{s}$, translating to a peak velocity of $24.1 \mathrm{~cm} / \mathrm{s}$. A volume rate of 16.4 volumes per second is obtained, and estimated flow rates based on nine steered planes within the volume are investigated. A positive bias is found for all investigated planes lying in the range from $6.5 \%$ to $21.2 \%$ with the standard deviation being less than $4 \%$ for all cases. It is concluded that volumetric 3-D vector flow estimation is feasible with an RCA array with only 124 elements.
\end{abstract}

\section{INTRODUCTION}

Volumetric B-mode imaging has previously been achieved with fully populated $N \times N$ 2-D matrix arrays. However, the large number of connections in a fully populated matrix array results in a complicated interconnect and a heavy processing task, which hinders a real-time implementation. As an alternative to the fully populated matrix array, the rowcolumn addressed (RCA) 2-D array was suggested [1], [2], [3]. In an RCA array, elements are accessed by either their row or column index, effectively reducing the total number of elements and channels in the interconnect to $2 N$.

Despite the significant reduction in element count for a RCA array, probes for experimental use have shown convincing results for both imaging [4] and 3-D vector flow estimation [5]. The imaging and volumetric power Doppler performance of an emulated 2-D RCA array was also lately investigated and compared with a corresponding matrix array [6].

This paper presents 3-D vector flow estimation in a full volume and expands on previous work, where a transmit sequence was designed to acquire $3-\mathrm{D}$ vector flow estimates in a plane using an RCA array [5]. The extra spatial dimension was achieved by redesigning the transmit sequence and modifying the post processing steps. With 3-D vector flow information present in a full volume, new complex blood dynamics can be investigated as well as user dependency can be reduced.

Section II presents the measurement materials and methods applied, section III describes the experimental setup, section IV presents and results, and section $\mathrm{V}$ provides conclusions.
TABLE I

TRANSDUCER PARAMETERS

\begin{tabular}{ll}
\hline \multicolumn{2}{c}{ Transducer } \\
Parameter & Value \\
\hline Trandsucer type & 2-D Row-Column \\
Number of elements in x & 62 \\
Number of elements in y & 62 \\
Pitch in x & $0.27 \mathrm{~mm}=0.53 \lambda$ \\
Pitch in y & $0.27 \mathrm{~mm}=0.53 \lambda$ \\
Width & $0.245 \mathrm{~mm}$ \\
Kerf & $0.025 \mathrm{~mm}$ \\
Sampling frequency & $35 \mathrm{MHz}$ \\
Center frequency & $3.0 \mathrm{MHz}$ \\
Footprint size & $1.67 \times 1.67 \mathrm{~cm}^{2}$ \\
\hline
\end{tabular}

\section{MATERiAls \& METHODS}

\section{A. Transducer array and scanner}

An piezoelectric RCA 2-D array [7], [4] with 62+62 elements and roll-off hardware apodization [8] was used, with properties as described in Table I. The probe was connected to the ultrasonic research scanner SARUS [9] and raw RF data from all 124 channels were sampled at $35 \mathrm{MHz}$.

\section{B. Flow-rig system}

An in-house built flow-rig system was used to validate the estimated volumetric 3-D velocities. The flow-rig contains a long inlet of $1.2 \mathrm{~m}$ which ensures a steady laminar parabolic flow profile at the measuring site. Blood mimicking fluid is driven inside the rubber vessel $(R=6 \mathrm{~mm})$ by a centrifugal pump in a closed loop circuit. The volume flow $Q$, is measured with a MAG 1100 flow meter (Danfoss, Hasselager, Denmark), which, due to the assumption of a laminar parabolic flow, can be translated to a peak velocity $v_{0}$ via the relation $v_{0}=2 Q /\left(\pi R^{2}\right)$.

\section{The transverse oscillation method}

Conventional use of transverse oscillation (TO) velocity estimator requires emissions weakly focused in a point [10], [11]. After each transmit event, three lines are beamformed; a center line used for the axial velocity estimate, and two lines spatially separated by $\pm \lambda_{x} / 8$, where $\lambda_{x}$ is the lateral wavelength, required for the transverse velocity estimate. Thus, from one transmit event 2-D vector flow information can be extracted along the beamformed centerline. With RCA arrays, however, focusing will result in a focal line, rather than 


\section{Volumetric Sequence}

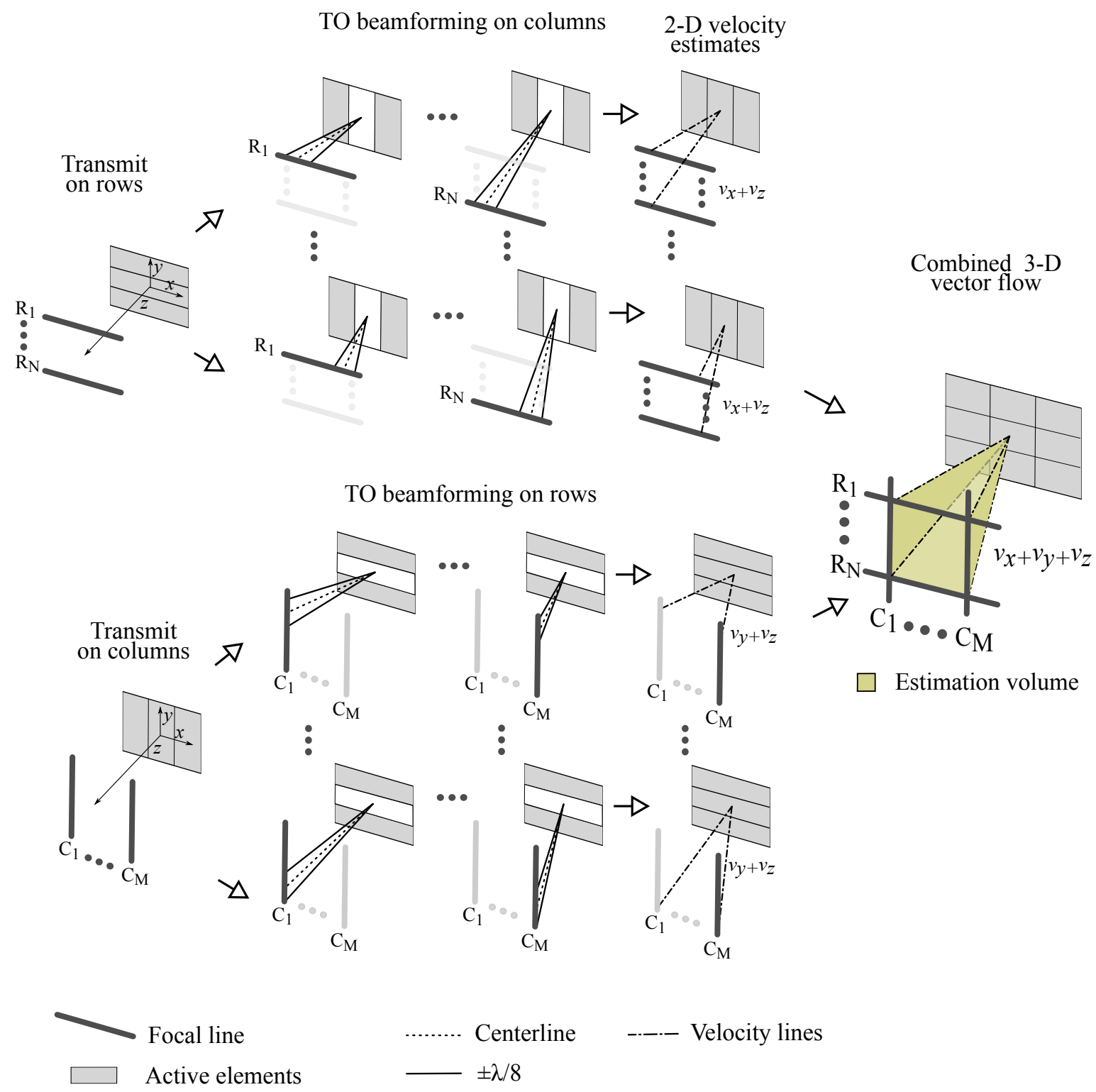

Fig. 1. The RC sequence for obtaining volumetric 3-D vector flow using TO: first, the $\mathrm{N}$ row emissions are made followed by the $\mathrm{M}$ column emissions. For each row emission, 3-D velocities are estimated in the plane defined by the focus line and the center of the emitting aperture. To make this, three lines (center and $\pm \lambda_{x} / 8$, where $\lambda_{x}$ is the lateral wavelength) are beamformed for each line along which estimates are desired using the signals received by the column elements. This yields the velocity components in the $x$ and $z$-directions. By similarly transmitting with columns and receiving with rows, the $y$ and $z$-components are found. These are then combined to attain the 3-D vector information.

a focal point, due to the tall element dimensions. This can be exploited to beamform several TO pairs along the focal line, such that 2-D vector flow can be estimated in an entire plane from one single transmit event [5] as illustrated in Fig. 1.

\section{Emission sequence}

A plane-by-plane 3-D volumetric vector flow imaging emission sequence was designed by expanding the single plane approach described in previous work [5]. A schematic illustration of the applied steered transmit sequence is seen in Fig. 1. As described in Section II-C, 2-D vector flow can be obtained in an entire plane from each transmit event. By transmitting $N$ distinguishable steered focused emissions by only exciting row elements and perform TO beamforming on each of the events, results in $N$ planes in a volume containing 2-D vector flow estimates. By interleaving the sequence with $M$ steered focused emissions where only column elements are excited, yields 2-D vector flow information also in the orthogonal dimension. Combining the 2-D vector flow information from the row and column emissions results in volumetric 3-D vector flow in the intersections of the $N$ and $M$ planes as illustrated 


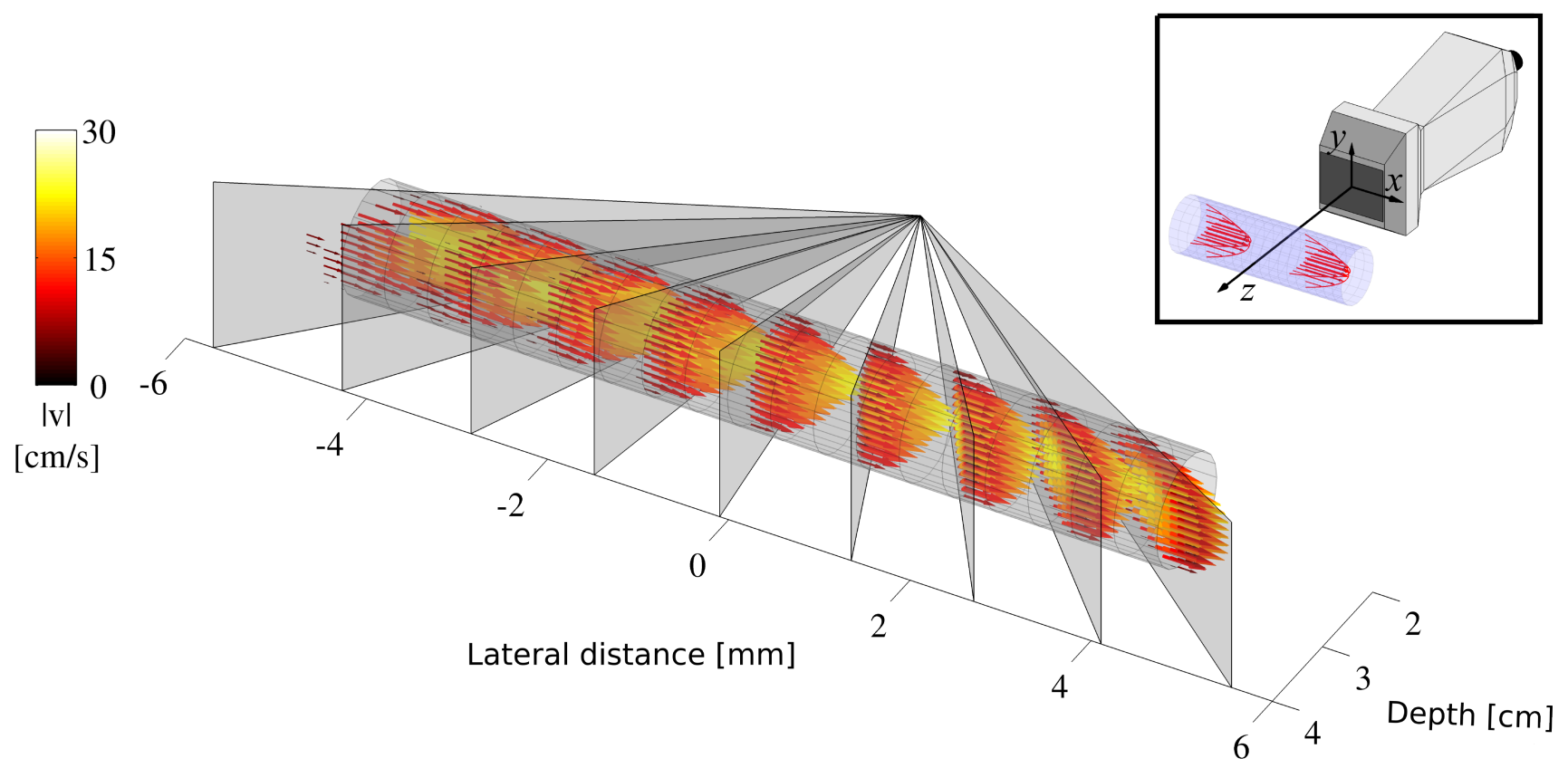

Fig. 2. Volumetric 3-D vector flow obtained in the flow-rig displayed for the nine cross-planes.

in Fig. 1. The repeating volumetric sequence is schematically written as

$$
\begin{array}{ccc}
C_{1} \rightarrow C_{2} \rightarrow \ldots C_{M} \rightarrow R_{1} & \rightarrow R_{2} \rightarrow R_{3} \rightarrow \ldots R_{N} \\
\vdots & \vdots & \vdots \\
C_{1} & \rightarrow C_{2} \rightarrow \ldots C_{M} \rightarrow R_{1} \rightarrow R_{2} \rightarrow R_{3} \rightarrow \ldots R_{N},
\end{array}
$$

where $C_{i}$ indicates focal line index $i$ when emitting with column elements and $R_{i}$ similarly for row elements.

The volumetric sequence consisted of $N=11$ row emissions and $M=9$ column emissions and was designed to acquire continuous data. The row emissions were steered from $-15^{\circ}$ to $15^{\circ}$ in steps of $3^{\circ}$ and the column emissions from $-8^{\circ}$ to $8^{\circ}$ in steps of $2^{\circ}$. This produces estimates along the intersections of the $N \times M=99$ planes corresponding to a $16^{\circ} \times 30^{\circ}$ volume. The c-plane at $3 \mathrm{~cm}$ depth spans an area of $16.1 \mathrm{~mm} \times 8.4 \mathrm{~mm}$.

\section{E. Data processing}

The emission sequence was repeated 2240 times corresponding to 4.3 seconds of data. The data was beamformed offline on a Linux cluster using a delay-and-sum beamformer specialized for RCA arrays [8]. Velocities were estimated with averaging over 32 estimates yielding 70 independent velocity estimates for each point using the TO method.

The nine scan-planes corresponding to cross-sections of the vessel are extracted for volume flow estimation. Volume flow is calculated by integrating the angle corrected estimates across each cross-sectional plane. The bias with respect to the flow rate reported by the flow rig and standard deviations are calculated for the volume flow through each scan plane.

\section{EXPERIMENTAL SETUP}

With the described probe and scanner a measurement was performed with the volumetric 3-D emission sequence. The applied transmit frequency was $3.0 \mathrm{MHz}$ and the pulse repetition frequency $\left(f_{p r f}\right)$ was $10.5 \mathrm{kHz}$. For the continuous data acquisition sequence presented here with $M+N=20$ emissions and averaging over 32 estimates, 16.4 independent 3 -D vector flow volumes per volume are attained.

The flow rate chosen in this setup was $13.7 \mathrm{~m} \mathrm{~L} \mathrm{~s}^{-1}$, translating to a peak velocity of $24.1 \mathrm{~cm} \mathrm{~s}^{-1}$. The center of the vessel was located $2.9 \mathrm{~cm}$ from the transducer's surface.

\section{RESUlts}

A volumetric representation of the mean out-of-plane velocity estimates are shown in Fig. 2. Based on the velocity component perpendicular to the cross-sectional area, the mean flow rate for each plane was calculated and are shown in Fig. 3. A positive bias was found for all of the steering angles, with the smallest at $2^{\circ}(6.5 \%)$ and the largest at $-8^{\circ}$ $(21.2 \%)$. Similarly, the smallest standard deviation was found for the plane steered by $8^{\circ}( \pm 3.0 \%)$ and the largest standard deviation was at a steering of $0^{\circ}( \pm 3.8 \%)$. The overall mean flow rate, based on the estimated value for each plane was 15.2 $\pm 0.7 \mathrm{~m} \mathrm{~L} \mathrm{~s}^{-1}$. However, erroneous velocities are estimated at larger steering angles, which may be due to the chosen lateral wavelength not matching the expected velocity range or that a further optimization of the beamforming for steered directions are required.

An illustration of the present parabolic flow is seen in Fig. 4, where the mean out-of-plane velocity component for the nine cross-sectional scan planes are shown. As expected, similar 


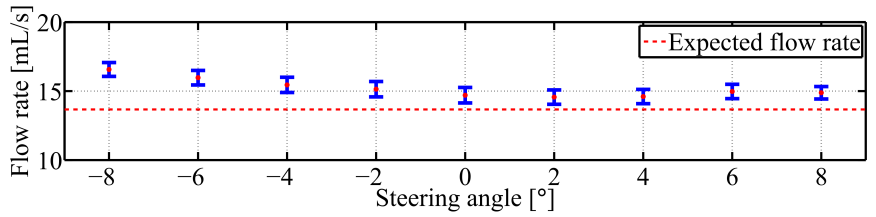

Fig. 3. Estimated flow rates for each of the the nine steered planes with the expected flow rate (dotted line) and standard deviation of the estimates denoted by the blue bar around the mean velocity estimate (red dot).

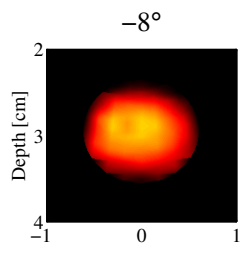

$-2^{\circ}$

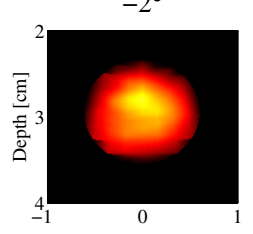

$4^{\circ}$
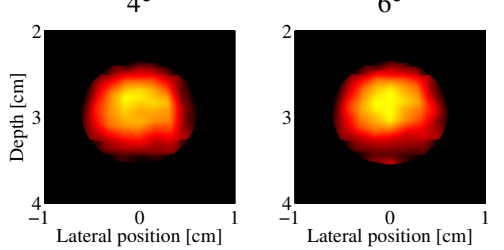

Lateral position $[\mathrm{cm}]$

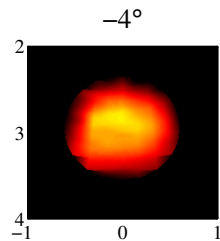

$2^{\circ}$
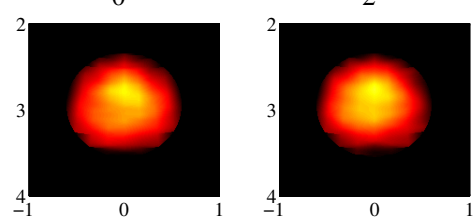

$8^{\circ}$

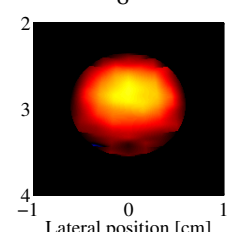

Lateral position $[\mathrm{cm}]$

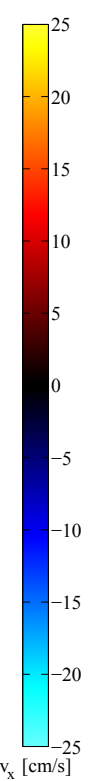

Fig. 4. Mean out-of-plane velocity for the 9 cross-sectional planes steered from $-8^{\circ}$ to $8^{\circ}$ in steps of $2^{\circ}$ averaged from 70 frames.

profiles with similar peak-velocities are seen across all steering angles.

\section{CONCLUSION}

This work demonstrates that volumetric 3-D vector flow can be measured with a 2-D RCA array with only 124 channels at a volume rate of 16.4 volumes per second. Measurements in a flow rig with laminar, parabolic flow yield a precision better than $4 \%$ and a bias below $21.2 \%$ in a sector of $16^{\circ} \times 30^{\circ}$.

\section{ACKNOWLEDGMENT}

This work was supported by grant 82-2012-4 from the Danish National Advanced Technology Foundation and by BK Ultrasound Aps.

\section{REFERENCES}

[1] C. E. Morton and G. R. Lockwood, "Theoretical assessment of a crossed electrode 2-D array for 3-D imaging," in Proc. IEEE Ultrason. Symp., 2003, pp. 968-971.

[2] C. H. Seo and J. T. Yen, "64 x 64 2-D array transducer with row-column addressing," in Proc. IEEE Ultrason. Symp., vol. 1, 2006, pp. 74-77.

[3] C. E. M. Démoré, A. Joyce, K. Wall, and G. Lockwood, "Real-time volume imaging using a crossed electrode array," IEEE Trans. Ultrason., Ferroelec., Freq. Contr., vol. 56, no. 6, pp. 1252-1261, 2009.

[4] T. L. Christiansen, M. F. Rasmussen, J. P. Bagge, L. N. Moesner, J. A Jensen, and E. V. Thomsen, "3-D imaging using row-column-addressed arrays with integrated apodization - part II: Transducer fabrication and experimental results," IEEE Trans. Ultrason., Ferroelec., Freq. Contr. vol. 62, no. 5, pp. 959-971, 2015.

[5] S. Holbek, T. L. Christiansen, M. B. Stuart, C. Beers, E. V. Thomsen, and J. A. Jensen, "3-D vector flow estimation with row-column addressed arrays," IEEE Trans. Ultrason., Ferroelec., Freq. Contr., vol. 63, no. 11, pp. 1799-1814, 2016.

[6] M. Flesch, M. Pernot, J. Provost, G. Ferin, A. Nguyen-Dinh, M. Tanter, and T. Deffieux, "4D in vivo ultrafast ultrasound imaging using a rowcolumn addressed matrix and coherently-compounded orthogonal plane waves," Phys. Med. Biol., vol. 62, pp. 4571-4588, 2017.

[7] M. Engholm, T. L. Christiansen, C. Beers, J. P. Bagge, L. N. Moesner, H. Bouzari, A. Lei, M. Berkheimer, M. B. Stuart, J. A. Jensen, and E. V. Thomsen, "A hand-held row-column addressed CMUT probe with integrated electronics for volumetric imaging," in Proc. IEEE Ultrason. Symp., 2015, pp. 1-4.

[8] M. F. Rasmussen, T. L. Christiansen, E. V. Thomsen, and J. A. Jensen, "3-D imaging using row-column-addressed arrays with integrated apodization - Part I: Apodization design and line element beamforming," IEEE Trans. Ultrason., Ferroelec., Freq. Contr., vol. 62 , no. 5, pp. 947-958, 2015.

[9] J. A. Jensen, H. Holten-Lund, R. T. Nilsson, M. Hansen, U. D. Larsen, R. P. Domsten, B. G. Tomov, M. B. Stuart, S. I. Nikolov, M. J. Pihl, Y. Du, J. H. Rasmussen, and M. F. Rasmussen, "Sarus: A synthetic aperture real-time ultrasound system," IEEE Trans. Ultrason., Ferroelec., Freq. Contr., vol. 60, no. 9, pp. 1838-1852, September 2013.

[10] J. A. Jensen and P. Munk, "A new method for estimation of velocity vectors," IEEE Trans. Ultrason., Ferroelec., Freq. Contr., vol. 45, no. 3, pp. 837-851, 1998.

[11] J. A. Jensen, "A new estimator for vector velocity estimation," IEEE Trans. Ultrason., Ferroelec., Freq. Contr., vol. 48, no. 4, pp. 886-894, 2001. 